\title{
Mediação Pedagógica: Reflexões sobre o Olhar Estético em Contexto de Escolarização Formal
}

\author{
Alice Casanova dos Reis \\ Andréa Vieira Zanella ${ }^{1}$ \\ Kelly Bedin França \\ Sílvia Zanatta Da Ros \\ Universidade Federal de Santa Catarina
}

\begin{abstract}
Resumo
Neste texto é analisada a mediação pedagógica no processo de constituição do olhar estético, a partir de dois momentos de reflexão coletiva sobre o processo vivido por um sujeito numa oficina de pintura. A atividade estética relatada foi proposta a acadêmicos de psicologia da Universidade Federal de Santa Catarina regularmente matriculados em uma disciplina optativa intitulada "Psicologia da Criatividade". Para a coleta de dados, optou-se pela videografia. A análise fundamentou-se no arcabouço teórico da psicologia histórico-cultural, priorizando discussões sobre a percepção enquanto atividade semioticamente mediada e as tramas que entrelaçam a produção e apropriação de significações num contexto de ensinar e aprender. Finalmente, através do discurso da protagonista da ação, foram identificados elementos que apontam para o reconhecimento de que a obra por ela produzida, ao engendrar múltiplos sentidos para os sujeitos em relação, pôde ser percebida através de outros ângulos, inusitados e imprevisíveis, possibilitando um novo olhar.

Palavras-chave: Mediação pedagógica; olhar estético; contextos de ensinar e aprender.
\end{abstract}

Pedagogical Mediation: Reflections about the Aesthetics Look

\begin{abstract}
This text analyses the mediation in the construction process of the aesthetics look from two moments of collective reflection about the process, which a person went through during a painting workshop. The reported aesthetics activity was proposed to Santa Catarina Federal University academicians who were regularly registrated in a discipline entitled Creativity Psychology. For collecting data, they have chosen the videography. The analysis was built on theoretical framework of historical and cultural psychology, it becomes a priority to discuss the perception as semiotically mediated activity and the webs which interlace the production and the appropriations of significance in a teaching and learning context. Finally, through the protagonist speech of the action, elements have been identified that point to the fact that it is possible to recognize that the work produced, engendering multiples senses for the people related, can be noticed through other unusual and unpredictable angles, making an a new look.

Keywords: Pedagogical mediation; aesthetics look; teaching and learning contexts.
\end{abstract}

O presente trabalho consiste em um recorte do conjunto de reflexões que vimos desenvolvendo a partir dos resultados obtidos com a pesquisa "Criatividade e Constituição do Sujeito em Contexto de Ensinar e Aprender: uma análise à luz da Psicologia HistóricoCultural". Abordam-se aqui as possibilidades de mudança no olhar de um sujeito, a partir das mediações realizadas por professores em um contexto de escolarização formal. As discussões centram-se na constituição da percepção estética através da participação do sujeito em vivências deliberadamente mediadas por educadores, onde o criar

\footnotetext{
${ }^{1}$ Endereço para correspondência: Universidade Federal de Santa Catarina, Departamento de Psicologia, Campus Trindade, 88010970 , Florianópolis, SC. Fone: 3319283.E-mail: azanella@cfh.ufsc.br
}

é um ponto de intersecção entre a ação prática e a reflexão teórica. As conclusões, portanto, referem-se às diversas mediações engendradas em um contexto educativo e seus resultados no que se refere à constituição do sujeito, mais especificamente à constituição do olhar estético.

\section{Sobre o Contexto e os Procedimentos Utilizados}

As análises aqui apresentadas tiveram como foco dois momentos de um processo de ensinar e aprender em um contexto de escolarização formal, momentos esses caracterizados pelo processo dialógico de produção de significações sobre a experiência vivida por um dos alunos. A atividade estética em torno da qual esses dois momentos foram recortados decorreu de uma oficina de desenho, proposta a acadêmicos de psicologia da Universidade Federal de Santa Catarina, regularmente 
matriculados em uma disciplina optativa ${ }^{2}$ que compõe a grade curricular do curso.

Necessário esclarecer que a programação da disciplina compreendia aulas teóricas, à luz da Psicologia HistóricoCultural, e oficinas estéticas, com foco em diferentes modos de expressão artística, como música, artes visuais e dança. O recorte aqui feito refere-se, portanto, a uma dessas oficinas.

O primeiro momento analisado foi o diálogo estabelecido entre aluna e professor, a respeito do movimento empreendido pela primeira no decorrer da vivência estética proposta por ele. Trata-se de um momento significativo de embate de significações a partir da confrontação dos respectivos pontos de vista sobre o vivido. O segundo momento destacado para análise foi a fala da aluna na aula seguinte, através da qual refletiu sobre a discussão travada com o professor.

Os procedimentos escolhidos para a coleta e análise de dados foram a videografia ${ }^{3}$ e a análise microgenética ${ }^{4}$, pois permitem registrar e compreender a intrincada trama de mediações nos processos dialógicos travados nas/ pelas relações interpessoais. Através desses processos dialógicos se estabelece o jogo dialético entre diferentes modos de perceber e compreender a experiência, falas que nascem do entrelaçamento mutuamente intenso entre o cognitivo e o afetivo, e através das quais significados e sentidos são coletivamente produzidos.

O sujeito, de agora em diante denominado Cláudia ${ }^{5}$, foi selecionado dentre os 11 alunos que participaram da pesquisa porque em seu processo evidenciaram-se elementos que possibilitaram uma reflexão sobre o modo de ver e significar tanto a sua produção estética quanto a si mesmo como sujeito criador. A escolha de dois episódios dentre todo o acervo de imagens registradas, por sua vez, levou em conta, no diálogo entre professor e alunos, os momentos em que ocorreu a maior quantidade e qualidade de mediações do educador direcionadas a essa reflexão sobre o olhar, e os momentos em que o sujeito se posicionou como protagonista do processo vivido, processo penoso e pesado, pensado e repensado, enfim re-ver-enciado.

\footnotetext{
2 A disciplina em questão intitulava-se "Psicologia da Criatividade" e compreendia 36 horas-aula, sendo ministrada no decorrer de um semestre letivo (2001.1) pelas duas profesoras que assinam este artigo.

${ }^{3}$ Sobre videografia ver Dessen (1995) e Meira (1994).

${ }^{4} \mathrm{~A}$ análise microgenética é discutida por Goés (2000).

${ }^{5}$ Nome fictício.
}

As análises desenvolveram-se apoiadas no arcabouço teórico da psicologia histórico-cultural, tendo como eixo de reflexão o processo de constituição do sujeito em contextos de escolarização formal. Mais especificamente, o foco de análise consistiu na possibilidade de constituição do olhar estético, como uma das formas possíveis de percepção, enquanto processo psicológico semioticamente mediado.

\section{Considerações Teóricas}

A questão do olhar vem se constituindo como um dos principais temas de reflexão na contemporaneidade. Se por muito tempo a problematização construiu-se em torno da afirmação ou da negação de um olhar contemplativo, compreendido como a (des)coberta de um sentido que se supunha como dado, inerente às coisas, ou seja, como o (des)velamento de uma realidade anterior e independente do olhar, hoje já não é mais possível apresentar o problema nesses termos: mudou o olhar e mudaram os pontos de vista a partir dos quais se busca a sua compreensão.

O olhar não é considerado um receptor passivo daquilo que é, mas uma atividade de produção e reprodução do que, em razão disso, é enquanto está sendo. A temporalidade desse olhar é atestada através do exame de sua construção histórica e social, a partir do desenvolvimento de percepções que caracterizam modos de ver engendrados nas/pelas relações sociais, cujas especificidades são datáveis. Tais esquemas perceptivos constituem-se não somente como filtros seletores e organizadores daquilo que importa ver dentre a ampla variedade de estímulos visuais, mas também como esquemas de significação desses estímulos (Vázquez, 1999), o que define esse olhar como inexoravelmente mediado em sua atividade de perceber as coisas do mundo.

A percepção enquanto processo psicológico, no entanto, nem sempre foi mediada. Luria (1979) explica como, ao longo do desenvolvimento filogenético, tornouse paulatinamente impossível ao olhar humano perceber diretamente um real que outrora se lhe apresentava como dado. Com a mediação semiótica ${ }^{6}$, o homem e os produtos da sua atividade deixam de ser simples elementos da natureza, convertendo-se não em uma realidade dada enquanto algo em si, mas em uma dada realidade, ou seja, uma realidade específica, a cujo ser é próprio possuir

\footnotetext{
${ }^{6}$ A mediação semiótica, fundamento do psiquismo humano, é pressuposto da teoria de Vygotsky (1995) e amplamente discutida por Pino (1991, 1995).
} 
um sentido, determinado justamente pela relação concreta que os homens com ela estabelecem.

Destaca-se assim um pressuposto fundamental para se pensar a percepção humana: os elementos que entram em sua experiência visual não fazem parte do real, embora façam parte da realidade, pois possuem de fato uma existência física. Essa existência física, porém, não é mais aquela já perdida que caracterizava o mundo da natureza, mas sim a de uma realidade significada, portanto criada, que constitui o mundo da cultura. Em razão disso, "Se há demostrado experimentalmente que no podemos crear condiciones que separen funcionalmente nuestra pecepción de la atribución de sentido del objeto percebido" (Vygotsky, 1992, p. 359).

Tal processo de significação, de produção, socialização e apropriação de sentidos, enfim, de constituição de uma realidade especificamente humana, aconteceu e ainda acontece sempre marcado por aquilo que caracteriza as relações sociais. São sentidos originalmente enraizados em uma realidade partilhada por seres humanos, portanto sentidos que são ao mesmo tempo singulares e compartilhados. Estes sentidos perduram no tempo, para além do âmbito vivencial em que se originaram, não porque, depois de comcebidos, sejam atemporal e inerentemente percebíveis para os seres humanos. Ao contrário, persistem porque são constantemente por eles percebidos enquanto sentidos consentidos, os quais são re-conhecidos naquilo que é visto a partir de um olhar que busca certa constância significativa na sua experiência e empenha-se, na verdade, em ver no visto o revisto, revisitar o outrora visto no agora assim reavistado.

Tal movimento se dá a partir do momento em que os sentidos ganham estatuto de significados. Ou seja, o significado é um sentido consensualmente conferido a um certo modo de se relacionar com uma realidade compartilhada e que se encontra referido numa representação a que se convencionou arbitrariamente a qualidade de lhe ser referente.

Desse modo, Vygotsky diferencia o significado como uma zona de sentido caracterizada por sua relativa estabilidade, apontando, entretanto, que os significados não são imutáveis, posto que são engendrados na dinâmica que se estabelece entre o signo e o contexto de sua utilização. Como signo, "A palavra incorpora, absorve de todo o contexto com que está entrelaçada os conteúdos intelectuais e afetivos e começa a significar mais ou menos do que contém seu significado quando a tomamos isoladamente e fora do contexto..." (Vygotsky, 2001, p. 466). Atribuir sentido, por sua vez "...es propriedad de la percepción del adulto y no del niño, que surge en un grado determinado, que es producto del desarrollo y que no está dada desde el principio" (Vygotsky, 1992, p. 361).

Desenvolveu-se assim um sistema convencionado de significações que possibilitam a referência a certos sentidos conferidos a uma realidade. Uma vez referida ou significada, abre-se para o homem a possibilidade de se desvincular desse realidade enquanto vivencial presente, para, justamente através da mediação semiótica, remeter-se hoje tanto ao passado quanto ao futuro. Ou seja, a mediação dos signos possibilita presentificar algo que é permanentemente (re)visto e revisado, significado e ressignificado, enfim, constantemente (re)produzido, a partir de um olhar que é ele mesmo constituído em condições históricas e sociais específicas.

Afirmar a constituição histórica do olhar humano implica em considerar que a percepção visual caracteristicamente humana não é natural, ou seja, não é dada desde o princípio, nem tampouco é alguma capacidade inata que, para se manifestar, necessita somente do toque mágico de um estímulo ambiental adequado. Implica em compreender esse olhar como indubitavelmente produzido, porquanto sua apreensão não é de uma realidade dada, mas de uma realidade criada, ou seja, cultural. Não existe, portanto, "o olhar", mas diferentes modos de ver segundo a referência do que é visto a sistemas específicos de atribuição de sentidos culturalmente produzidos.

Olhar é assim compreendido não como processo neutro de percepção em seu aspecto funcional, mas como verdadeira visão de mundo, construída a partir dos dispositivos visuais de apreensão e avaliação da realidade característicos de uma época e um lugar. No texto "A Gênese Social do Olho", Bordieu (1996, p. 353), aponta de que modo o olhar, no caso a visão de mundo renascentista, se constitui histórica e socialmente: “ 'olho moral e espiritual' modelado pela 'religião, a educação, os negócios', o 'olho do quattrocento' não é mais que o sistema dos esquemas de percepção e de apreciação, de julgamento e de fruição que, adquiridos nas práticas da vida cotidiana, na escola, na igreja, no mercado, escutando cursos, discursos ou sermões, medindo montes de trigo ou peças de lã ou resolvendo problemas de juros compostos ou de seguros marítimos, são empregados em toda existência ordinária e também na percepção das obras de arte".

A realidade é "apreendida", portanto, via olhar, histórico e socialmente construído, que caracteriza um modo de ver o mundo através de determinada lente, de um ângulo específico. Assim constitui-se a percepção cotidiana do mundo, sendo este pré-ordenado segundo estruturas de significação de certa forma rígidas: 
Os hábitos, estruturas ou esquemas perceptivos com os quais, numa determinada sociedade, se organizam os dados sensíveis tendem a converter-se em normas ou regras rotineiras que enfraquecem a capacidade de enriquecer os dados sensíveis com novos significados. A percepção na vida cotidiana tende a repetir-se em esquemas invariáveis e, portanto, a automatizar-se. (Vázquez, 1999, p. 139)

A percepção estética, em contrapartida, é um olhar mais livre na sua apreensão significativa do mundo, pois busca outros ângulos de leitura, não para ver o objeto em sua présuposta verdade, mas procurando, na relação estética com ele estabelecida, produzir novos sentidos para a configuração de realidades outras.

Os sentidos produzidos e apreendidos através da percepção estética resultam de processos psíquicos complexos, caracterizados por um intenso imbricamento dos aspectos afetivos, volitivos e cognitivos do sujeito. Teplov (1977, p. 132) aponta as várias atividades psíquicas que atuam conjuntamente na percepção estética: "A percepção da arte é um processo activo, que incorpora momentos motores (ritmo), experiência emocional, actividade imaginativa e 'operações do pensamento"'.

Em virtude das características apontadas, a percepção estética é criativa, pois não se esgota no reconhecimento do mesmo naquilo que percebe, ao contrário, amplia as possibilidades significativas, expandindo assim as fronteiras do perceptível. A especificidade desse olhar reside em sua originalidade, qualidade que permite denominá-lo de "olhar do estrangeiro" (Peixoto, 1999) porque vê as coisas como se fosse pela primeira vez, (re)significando o instituído, vendo o diferente onde o olho dos "nativos" já havia se habituado a somente enxergar o mesmo, o igual.

Desse modo, o olhar estético é também crítico, pois se atribui

... a missão de elevar nossa capacidade de surpresa ou alheamento ante o cotidiano, o banal, o evidente por si mesmo. O homem resiste assim a deixar-se integrar nessa realidade que se vive a cada dia e se afirma perante ela com poder desautomatizador, crítico, que exerce com a arte. (Vázquez, 1999, p. 152)

Esse olhar de estranhamento, característico da percepção estética, é, portanto, uma das formas de o sujeito reconhecer e ampliar suas possibilidades, seu poder reflexivo e criativo, pois permite que se retire a marca de familiaridade da realidade, que não se tome a máscara que lhe dá um sentido único, mas que essa possa ser vista como polissêmica e multifacetada. Esse olhar, enfim, possibilita, conforme nos aponta a epígrafe que inaugura este texto, "temperar a realidade", buscar, num participando, "um sempre novo assando".

\section{A Atividade, os Sujeitos e seus Olhares}

Uma das oficinas realizadas na disciplina Psicologia da Criatividade foi escolhida como contexto para o recorte analítico aqui proposto. Nesse dia, o grupo de alunos e as duas professoras responsáveis pela disciplina direcionaramse ao Colégio de Aplicação da UFSC, onde se desenvolveu uma oficina estética de desenho, coordenada por dois artistas plásticos ${ }^{7}$. Primeiramente, os alunos foram convidados a observar o Espaço Estético ${ }^{8}$, um local em cujas paredes estavam expostos, naquele dia, vários trabalhos artísticos de alunos do Colégio de Aplicação (desenhos em papel pardo). Esses foram comentados pelos professores no que diz respeito ao material utilizado - grafite - e às características dos traços.

A seguir, os sujeitos encaminharam-se para um amplo "galpão" ", onde foram mobilizados para a vivência do processo de criação, recebendo como proposta de atividade experimentarem novas linhas de desenho no livre contato com o material que foi posto à disposição Este consistiu em grandes retângulos de papel pardo, suspensos nas paredes e cubos negros feitos de parafina perfumada, com aproximadamente $5 \mathrm{~cm}$ de comprimento, $3 \mathrm{~cm}$ de largura e espessura de $1 \mathrm{~cm}$. Destaca-se a abertura oferecida por esse instrumento, pois à medida que o cubo corria pelo papel desgastava-se, assumindo outra forma, possibilitando com isso alternativas no traço e na posição da mão/dedos que o compõem. Necessário ressaltar também que com outros formatos, diferentes dos instrumentos convencionais para a escrita, como lápis, caneta, e giz de cera convencional, o cubo impõe à mão que o utiliza posições "estranhas" e, por que não dizer, em alusão ao destacado por Peixoto (1999), estrangeiras.

A fala de Jacques que ora apresentamos é o retrato desse convite:

(turno 1) Jacques - A proposta, a primeira situação é vocês se depararem com um plano, desenharem sem se

\footnotetext{
${ }^{7}$ Os artistas em questão chamam-se Galheigo Jacques Ferreira e Fabíola Burigo Cerimbelli da Costa e ministram aulas de alfabetização estética no Colégio de Aplicação da UFSC. Apresentamos aqui nossos agradecimentos pela importante colaboração em nossa pesquisa, a qual esperamos retribuir com esse texto.

${ }^{8}$ Trata-se de um espaço permanente no Colégio de Aplicação, utilizado para exposições efetivadas pela equipe de artes visuais do colégio e para interações do universo escolar com seu entorno.

9 “Galpão" é a denominação utilizada pela comunidade escolar para se referir a um amplo vão entre alas de salas de aula, com aproximadamente $12 \mathrm{~m}$ de largura e $30 \mathrm{~m}$ de comprimento.
} 
apoiar na realidade objetiva. Vamos descobrir a linha, esse jogo de linhas... risquem... chamo a atenção para alguns aspectos; comportamento estereotipado da mão; vícios. $\mathrm{O}$ gesto se mantém. Quero que vocês percebam a linha, o movimento, tenham consciência do gesto, do movimento do braço, percebam a linha que está sendo desenhada. Desarticulem mesmo.

Brinquem com a linha, caminhem pela folha, à medida que vocês forem trabalhando eu vou chegar, discutir, dar uma olhada, perceber que linhas estão ali. E fazer confrontos, sobretudo perceber possibilidades outras de se expressar através da linha, criar, ser mais criativo do que o que você já construiu.

Os alunos engajaram-se entusiasticamente na atividade, que teve duração aproximada de $1 \mathrm{~h} 30 \mathrm{~min}$, entregando-se cada qual a sua experiência com as linhas. Enquanto isso, os coordenadores da atividade, na condição de artistas socialmente reconhecidos e de professores, iam acompanhando o trabalho, conversando com cada aluno em particular sobre o que este estava produzindo.

Resgataremos dois momentos de reflexão coletiva institucionalizada ${ }^{10}$ sobre o processo vivido. O primeiro momento ocorreu nesse mesmo dia, após os alunos trabalharem e terem suas produções apreciadas e discutidas informalmente tanto pelos artistas/professores quanto pelos colegas. Todos foram convidados a se dirigir a uma sala para conversarem sobre o processo e socializarem suas experiências. Jacques iniciou a conversa destacando algumas impressões:

(turno 2) Jacques - Alguns não queriam se deparar com a instabilidade que aquela situação estava colocando, para mim foi enriquecedor. Gostaria que vocês colocassem, para eu não sair daqui achando que foi em vão.

Os relatos vão se sucedendo, mediados por Jacques e Fabíola. Transcreveremos a seguir um trecho desse momento em que Cláudia e o coordenador Jacques confrontam seus pontos de vista sobre o processo por ela protagonizado:

(turno 3) Jacques - Eu falei para alguns alunos...O seu, né [aponta para Cláudia]...O trabalho dela já estava estabelecido, era uma paisagem e ela colocou...

(turno 4) Cláudia - Tu mandaste eu fazer alguma coisa e eu fiz aquele raio que tu falaste 'Á, isso aí eu gostei!'. E eu fiz porque tu pediste para eu ir lá e...[movimenta o braço]

\footnotetext{
${ }^{10}$ Designamos momentos de reflexão coletiva institucionalizada as situações em que a discussão do processo foi deliberadamente proposta pelas professoras da disciplina Psicologia da Criatividade - ainda que a primeira delas tenha sido coordenada pelos artistas/professores - as quais participaram da vivência em condição similar a dos alunos.
}

(turno 5) Jacques - Mas eu não indiquei o que você deveria fazer.

(turno 6) Cláudia - Não, nada!

(turno 7) Jacques - E foi uma linha que me chamou muito a atenção porque era uma linha que divergia de todas as outras e ela se sobressaía naquele jogo... já existia uma estrutura estabelecida, na qual você já tava 'Áh, não quero mexer mais, tá bom assim, não quero destruir'. Aí...há esse prazer ou algo assim mas...tá, essa emoção já está estabelecida, pronta, agora arrisca, mesmo que você se frustre, por que não se frustrar com o trabalho, com essa prática? Por que não descobrir? Não perdes oportunidade do erro no fazer, de perceber o erro, para que você depois caminhe por outro...enfim, quem sabe não é nesse erro que ensinamentos outros surjam? A linha é interessante, mas a maneira como foi colocada é que foi interessante, essa forma de riscar é interessante. É descoberta, é descobrir novas palavras, novas coisas, não se fechar, não ficar com um vocabulário prontinho, fechado, não em arte, eu acho que isso não...

(turno 8) Cláudia - É que eu acho que eu não gosto assim de abstrato...eu não conseguia desenhar coisas assim que nem ela tava desenhando (refere-se a uma colega), cada coisa que não tem significado.

(turno 9) Jacques - 'Não tem significado', aí ó...

(turno 10) Cláudia - Não sei, prá ela tem, mas eu não tava conseguindo ver o que que ela tava fazendo, que que é aquilo ali? E ela fazia, fazia, fazia. Não tinha como eu captar. E eu fiz o meu bonitinho, o meu significado: quero que fique bonitinho.

(turno 11) Jacques - O que é significado? Significa algo. É muito comum as pessoas diante de um trabalho abstrato: 'Áh, eu não gosto disso', mas ela não sabe porque ela não gosta. Sabe por que geralmente elas não gostam? Porque não têm onde se apoiar; é muito comum as pessoas ficarem 'Ai, parece uma lua lá, parece que tem um bicho aqui'... para que elas possam se apoiar e se sentir seguras. Aquela coisa: pega uma tela na parede da sua casa e dê uma inclinada, parece que o mundo está em desordem. Como precisa dessa verticalidade, dessa estrutura, dessas referências!

(turno 12) Cláudia - Eu não sabia o que significa, ela desenhava e eu não sabia o que significa e eu...

(turno 13) Jaqcques - Eu tinha uma aluna da $8^{a}$ série no ano passado, ela fez um desenho abstrato que ela não gostava, mas eu percebia que em certos locais tinha um tipo de uma linha que se cruzava que era muito comum e se repetia e eu mandei ela se apropriar daquilo. Aquilo acabou se tornando um símbolo que ela usou em vários trabalhos, ...acabou sendo a marca dela. Passou a significar. Aquilo era dela, ou seja, aquilo era ela. E eu chamei "Olha como isso se repete, 
se apropria disso, por que que entre tantas formas essa se repete? Porque eu acho que alguma coisa existe aí que deve ser interessante, então vamos nos apropriar dela!” E ela se apropriou dessa estrutura. São formas muito bonitas.

Essa discussão constituiu-se como uma primeira reflexão sobre a vivência estética de Cláudia que, coletivamente produzida, foi ali coletivizada. $\mathrm{Na}$ seqüência das reflexões, Cláudia e sua experiência não mais aparecem como protagonistas, o que volta a acontecer na semana seguinte. Ao iniciar a aula naquele dia, uma das professoras propôs que os alunos relatassem a experiência da semana anterior para uma colega que esteve ausente. O processo de Cláudia volta à tona, resgatado pela professora:

(turno 14) Prof 1 - A Cláudia eu lembro, foi uma que ficou bem incomodada com o trabalho, né?

(turno 15) Cláudia - Eu não desenhei o que ele queria... Era desenho abstrato, coisa assim, como ele disse, linhas espontâneas, que não tá estereotipado. E eu fui desenhando bem o concreto, bem paisagem, difícil de... 'Não', ele dizia, 'vai lá, destrói, faz um desenho diferente, pinta, faz linha assim'. E eu: 'como é que eu vou destruir?'. Aí eu fiz uma linha assim, um negócio, e ele achou o máximo, 'Ai, parece um raio!'. Mas é bom assim, ele fazer a gente querer mudar. Serviu para ver como eu não estava conseguindo fazer, de vez em quando é bom a gente parar e pegar uma folha e riscar, eu não tenho, nunca paro para desenhar ou para fazer coisa assim, para tentar criar alguma coisa,

(inaudível)

(turno 16) Cláudia - ...organizada, detalhista, chata. Eu falei 'É bem isso', ter medo de fazer...Ele notou na hora. Até meu signo ${ }^{11}$, detalhista, organizada, tudo direitinho, né, não querer mudar. Para ele acho que foi assim 'Meu deus, essa guria não quer fazer nada'. Ele deve ter achado horrível, assim, eu não ter feito o que ele queria...

(inaudível)

(turno 17) Cláudia - O que ele queria era que eu fizesse outra coisa 'Vai lá, arrisca, muda'.

\section{Discussão}

As falas transcritas oferecem indícios importantes para a compreensão do olhar estético, a possibilidade de sua constituição em Cláudia na situação analisada e do lugar que ocupam, nesse processo, as mediações de Jacques. Destaca-se inicialmente o modo como ele propôs aos alunos a atividade estética (turno 1): desde o princípio a ênfase recaiu sobre a experimentação do novo em termos de forma, da realização de novos movimentos de desenhar

\footnotetext{
${ }^{11}$ Cláudia refere-se aqui ao signo do zodíaco.
}

enquanto atividade consciente. Enquanto tal é deliberada, mediada pela intencionalidade que procura identificar marcas antigas e novas, romper com o cristalizado, com aquilo que foi naturalizado na expressão artística.

$\mathrm{Na}$ proposta que inaugurava a busca do novo não foi exigida a reprodução plástica da realidade objetiva, ao contrário, foi proposta a liberdade para a criação de linhas singulares, de expressões diferentes daquelas próprias e costumeiras ao sujeito, traços descomprometidos com qualquer ideal clássico de arte ou de beleza formal aprioristicamente estabelecidos. Jacques deixou, assim, o caminho aberto à criação e convidou todos a se lançarem na aventura de percorrê-lo, de olhos abertos para o novo: “...perceber possibilidades outras de se expressar através da linha...criar, ser mais criativo do que o que você já construiu".

Após a vivência estética, Jacques inicia o diálogo sobre a experiência apontando para a resistência de alguns alunos frente à instabilidade gerada pela situação proposta, (turno 2), resistência que se objetivou na permanência de padrões habituais de percepção e sua expressão em imagens. Problematizou, assim, a rigidez do traço (turno 3), destacando o momento inicial no processo de Cláudia, quando ela estava presa a um modo cristalizado, pré-estabelecido de expressão gráfica que resultou, no caso específico do desenho realizado por ela, em uma paisagem.

Referenciada, trazida ao cenário discursivo na condição de protagonista, Cláudia traz para o debate, no turno 4, um elemento pictórico de sua pintura ("o raio"), cuja criação remete a uma demanda de Jacques: "Tu mandaste eu fazer alguma coisa e eu fiz aquele raio que tu falaste 'Áh, isso aí eu gostei' e eu fiz porque tu pediste...”.

Interpelado, de certo modo acusado de direcionar o olhar e instabilizar as certezas, Jacques prontamente demarcou a pluralidade possível, a fluidez e irradiação desejada, pois não indicou o que ela deveria fazer (turno 5). Afinal, sua proposta era que cada um brincasse com as linhas, percebendo os automatismos de se expressar (turno 1) e conscientizando-se de novos gestos utilizados para desenhar.

Nesse momento de embate constatou-se uma das dificuldades a serem superadas no processo de constituição do olhar estético: a percepção cotidiana está acostumada à segurança resultante da tutelagem voluntária a uma linguagem visual compartilhada ${ }^{12}$, sendo o desconhecido muitas vezes

\footnotetext{
${ }^{12}$ Por linguagem visual compartilhada entende-se aqui a visão de mundo dominante em uma sociedade, mais especificamente um modo específico de percepção visual/categorial/cotidiana da realidade, a partir do qual se dá a experiência visual do mundo como organização do sensível através de esquemas perceptivo/significativos relativamente constantes. A partir desses esquemas os homens constróem o que se convencionou como a visão objetiva da realidade.
} 
fonte de medos. Assim, muitos sujeitos preferem permanecer no seguramente conhecido e previsivelmente igual a si mesmo do que se lançar ao novo, à percepção e expressão da diferença sobre a qual não há garantias prévias de aprovação e aplauso.

Essa dificuldade é reconhecida no turno 7, onde Jacques traz o raio - anteriormente mencionado por Cláudia - para o centro da reflexão, tomando-o como uma linha especial que se sobressaiu no desenho posto que divergiu do traçado predominante. Em meio ao estereótipo, à estrutura já estabelecida na pintura de Cláudia, o raio foi destacado por Jacques como uma linha de fuga, um elemento dissonante que ele valoriza enquanto uma possibilidade de descoberta do novo e diferente em meio ao mesmo e reiterante: "E foi uma linha que me chamou muito a atenção porque era uma linha que divergia de todas as outras e ela se sobressaía naquele jogo".

Com essa mediação, Jacques indica o arriscar-se como constituidor do olhar estético e a necessidade, de quem se propõe a realizar uma atividade estética, de lançar-se na aventura de inventar outros modos de perceber o mundo e de expressar-se. Ao se referir à experiência de Cláudia, questionou a razão do receio em enfrentar o risco de tentar o novo e incerto e destacou a frustração como parte positiva do processo de criar: "...agora arrisca, mesmo que você se frustre, por que não se frustrar com o trabalho, com essa prática? Por que não descobrir?”.

Mesclam-se, na fala deste educador, referências a dois aspectos que considera importantes na produção estética: o reconhecimento do "erro" como constitutivo do processo de criar, sendo este entendido não enquanto desvio indesejável de um caminho ideal de percepção e expressão artística, mas a partir de uma visão onde a razão de ser da arte é justamente a invenção de caminhos outros. Nessa perspectiva, o erro é somente uma outra possibilidade de acerto que traz um ensinamento novo sobre algo que já nos parecia seguramente conhecido. O outro aspecto diz respeito à frustração, ao desconforto, o que rompe com a ilusão de que a produção artística é puro deleite e prazer. Ao contrário, "Criar é fonte de júbilo para o homem, mas acarreta também sofrimentos conhecidos com o nome de torturas da criação. Criar é difícil, a demanda criadora nem sempre coincide com a possibilidade de criar..." (Vygotsky, 1990, p.49).

\footnotetext{
13 Oliveira encontra no Renascimento a gênese histórica do processo de racionalização e cientificização do olhar, destacando o papel nele desempenhado pelas técnicas de produção de imagens objetivas desenvolvidas pelos pintores renascentistas, sobretudo "...a perspectiva, um sistema que finalmente possibilitava à imagem tornar-se cópia fiel do mundo” (Oliveira, 1996, p.155).
}

Na continuação do episódio, Cláudia fala sobre a dificuldade encontrada nesse processo de abertura do vocabulário, ou seja, de desautomatização dos esquemas perceptivos/significativos, dizendo que não gosta de desenho abstrato, pois não gosta do que "não tem significado". Apresenta, assim, indícios sobre o modo como percebe o mundo em geral e a arte em particular: a partir de certos critérios de objetividade, que organizam o percebido segundo um sólido e concreto sistema de significados préestabelecidos, através dos quais se configura a ordenação racional e racionalizante do mundo. A arte assim ad-mirada é espelho do real e comprometida com esse ideal estético cujas raízes históricas encontram-se no Renascimento ${ }^{13}$.

Jacques logo interveio (turno 9 e 11), problematizando esse modo objetivista de relacionar-se com a arte, que para Cláudia reduzia as possibilidades de expressão a formas em que os significados se encontram aprioristicamente estabelecidos segundo uma leitura fechada. Em seu desenho os significados devem ser facilmente distinguíveis, facilmente acessíveis ao olhar, como se fossem dados a serem captados, excluindo assim as formas nas quais se torna necessário um diálogo do olhar com o objeto da percepção.

A mediação de Jacques no turno 11 veio confrontar o ponto de vista de Cláudia, questionando justamente essa necessidade das pessoas de se apoiarem em significados para que se sintam localizadas num mundo que assim thes parece ordenado, em virtude dessa intelegibilidade em que se sustentam. No entanto, na atividade desenvolvida, essa necessidade foi contraposta ao desafio de criar "a sua forma" de ver o mundo, a qual não implicava na negação dessas referências, mas em sua re-leitura, sua re-visão por parte do sujeito. Era, portanto, um desafio ao olhar, que visava à conscientização dessa necessidade de apoio no conhecido, de ênfase no significado, a qual diz respeito ao homem enquanto ser inexoravelmente social, na medida em que se relaciona a uma vontade de verdade fundamentada na fé de que a medida do certo e verdadeiro é a segurança de não se estar sozinho na própria crença.

Nesse sentido, o coordenador também relacionou a resistência das pessoas diante da arte abstrata ao fato desta não lhes oferecer um significado pronto, uma leitura fechada, algo conhecido em que se apoiar. Tal resistência apareceu claramente na fala de Cláudia sobre o desenho abstrato de uma colega (turnos 10 e 12), quando ela ansiosamente comunica: "eu não estava conseguindo ver o que ela estava fazendo...ela desenhava e eu não sabia o que significava...". Por que ela não estava conseguindo ver um significado naquela forma abstrata? Ela não via porque não existia de fato nenhum significado possível àquele desenho? Ou era 
porque seu olhar esperava que um significado lhe saltasse subitamente aos olhos? A arte visual abstrata diferencia-se de outras formas porque exige do espectador não o olhar cotidiano, não uma percepção que se limita a "constatar" o que supostamente já está dado no objeto estético, mas apresenta-se ao espectador como um convite a leituras múltiplas realizadas no encontro de seu olhar estético com aquela forma sensível oferecida pela obra de arte.

Essa dimensão criadora do olhar estético na produção e apreciação da obra de arte implica uma apropriação significativa da mesma, que se estabeleça um diálogo com a imagem em que sentidos possam emergir. É a esse processo que Jacques aludiu no turno 13, onde relatou como uma linha disforme, inicialmente insignificante para a menina que a desenhou, ao ser apropriada por ela, conforme the fora sugerido por ele, "Passou a significar. Aquilo era dela, ou seja, aquilo era ela".

Destaca-se aqui a importância fundamental do olhar estético na constituição do sujeito: $\mathrm{O}$ artista, ao atribuir sentido a uma determinada forma, trans-forma a mesma em símbolo. Já não é mais qualquer forma, mas uma forma que in-forma sobre o seu autor, através do modo como dá forma, como trans-figura em imagem, sentidos concernentes à singularidade do artista e à trama de intersubjetividades na qual ela é social e historicamente produzida, bem como objetivada e apreciada. Nesse processo de criação da obra de arte enquanto uma outra realidade, singular e socialmente concebida, o artista re-cria a si mesmo por seu intermédio, e nela se realiza também enquanto outro, diverso de si mesmo.

$\mathrm{Na}$ semana seguinte, reflexão sobre o processo vivido por Cláudia volta à tona quando uma das professoras (turno 14) relembra o desconforto demonstrado por ela relativamente à atividade desenvolvida na aula anterior. Se antes, no embate dialógico entre a aluna e o artista/professor da atividade, esta pareceu, através do modo como posicionou-se em suas falas, irredutível quanto à possibilidade de mudar seu ponto de vista sobre a arte, de certo modo invalidando a experiência do desenho abstrato posto que sem sentido, neste segundo momento contatam-se mudanças em sua argumentação.

Assim, no turno 15 Cláudia afirma não ter realmente se engajado na atividade proposta pelo coordenador ("Eu não desenhei o que ele queria. Era desenho abstrato... que não está estereotipado. E eu fui desenhando bem o concreto"), ou seja, admite sua dificuldade em destruir estruturas de percepção e expressão já cristalizadas e, de certo modo, estereotipadas. Revela com isso sua resistência em entrar numa relação com a realidade em geral e a arte em particular através de outro olhar, menos objetivista e concreto, menos orientado para re-ver sentidos previamente conhecidos. Por outro lado, reconhece a validade da experiência, (re)significando-a agora de modo positivo: "Mas é bom assim ele fazer a gente querer mudar... de vez em quando é bom a gente parar e pegar uma folha e riscar...para tentar criar alguma coisa".

No turno 16, Cláudia cita algumas características constitutivas de seu modo de ser e de ver o mundo, colocando-as como fatores que influenciaram sua atitude tanto durante a atividade estética, quanto durante a reflexão posterior sobre a mesma, travada entre ela e o coordenador. É interessante o modo como, por um lado, admite sua resistência à mudança, seu medo de fazer diferente, o qual foi, segundo ela, prontamente notado pelo coordenador; mas, por outro lado, justifica a postura assumida ao remeter as características citadas a um determinismo astrológico, considerando esse seu jeito que "não quer mudar" como "inerente" a seu ser: "Até meu signo, detalhista, organizada, tudo direitinho, né, não quer mudar..." (turno 16).

Apesar de anteriormente haver re-significado como válido o modo instigante como o coordenador provocou-a à mudança tanto de percepção quanto de expressão artística - a qual, como já foi afirmado, constitui-se não como reflexo do real, mas como objetivação em imagem de uma visão de mundo, ou seja, de um modo específico de ver/construir significativamente a realidade - no turno 17 Cláudia pareceu reiterar seu posicionamento inicial, uma vez que reafirma obstinadamente sua discordância em vivenciar como oportunidade de mudança a experiência proporcionada pela oficina estética de desenho: "O que ele queria era que eu fizesse outra coisa 'Vai lá, arrisca, muda'. Ele queria que eu fizesse, não eu".

De certo modo, Cláudia parece concluir sua reflexão sobre o processo vivido voltando ao ponto inicial, uma vez que, desde as primeiras falas aqui transcritas, ela afirma continuamente o desejo de permanência de seu olhar seguro, concreto, organizado e detalhista sobre um mundo assim visto de modo ordenado, através de significados "bonitinhos, direitinhos". A mudança, representada pelo elemento pictórico do raio, foi remetida por ela ao desejo do outro, porque afirma não ter feito voluntariamente aquele risco inoportuno em seu desenho. $\mathrm{O}$ raio para ela permanece como um elemento estranho, um invasor inserido posteriormente à conclusão de seu desenho, um risco que, se foi feito por ela, não foi porque realmente ela o quis fazer, mas por uma insistência exterior à qual acabou consentindo. O consentimento, por sua vez, atende a características do contexto em que a atividade foi

\footnotetext{
${ }^{14}$ Utilizaremos aqui o adjetivo "professor" para nos referirmos a Jacques, para marcar a condição pedagógica que sua fala ali assume.
} 
protagonizada: afinal, o embate travou-se entre "professor" 14 e aluna, artista e leiga, com lugares sociais e expectativas claramente demarcados.

\section{Conclusão}

Buscou-se, através da análise das falas transcritas, acompanhar o processo de constituição do olhar estético de um sujeito a partir de sua participação em uma oficina de desenho abstrato e das reflexões posteriores sobre a mesma, com destaque para as mediações realizadas pelo artista/ professor durante estas atividades. A discussão desenvolvida aponta para a intenção do mediador em constituir um olhar estético em Cláudia. Destacam-se, em suas intervenções, o modo como problematizou as formas estereotipadas; como convidou à experimentação de outras formas de perceber e de se expressar criativamente; como questionou o medo de arriscar-se ao novo; como desestabilizou a segurança de uma percepção limitada por um vocabulário pronto e instigou desafiadoramente à descoberta de novos traços, novas formas, novos sentidos. Todas essas características permitem compreender as estratégias utilizadas como deliberadamente orientadas para a constituição de um olhar estético.

Por outro lado, o modo como Cláudia experenciou essa proposta de desenhar abstratamente, sua resistência em engajar-se, em arriscar-se ao traçado de novos riscos, o modo obstinado como, ao ser confrontada pelo coordenador, defendeu seu ponto de vista, afirmou e reafirmou seu desejo de permanência ao modo costumeiro de percepção. Todas essas características permitem identificar um movimento de oposição e resistência à mudança permeando seu discurso.

Apesar disso, uma nova forma se insinuou em seu desenho, um risco que pode ter nascido de um súbito movimento de raiva em resposta à intervenção instigadora de Jacques, um raio que pode até ter tido, para sua criadora, o sentido de mandar o coordenador "para o raio que o parta!". Mas, independente do que talvez seja o seu sentido original, o raio de alguma maneira materializa esse processo "tempestuoso" vivido por Cláudia e anuncia outras possibilidades, de cortes e rupturas, de emergência de algo novo.

\footnotetext{
${ }^{15}$ Maurice Blanchot (1987), na reflexão que desenvolve sobre a questão da inspiração no processo de criação do artista, traz o erro não apenas como parte integrante do processo, mas como a verdadeira fonte da originalidade criativa:

...como se renunciar à derrota fosse muito mais grave do que renunciar ao êxito, como se aquilo a que chamamos o insignificante, o não-essencial, o erro, pudesse, àquele que lhe aceita o risco e se the entrega sem reservas, revelar-se como a fonte de toda a autenticidade. (p.174)
}

Assim, o destaque conferido ao raio por Jacques resultou, ao que suas intervenções indicam, do reconhecimento deste traço como o elemento dissonante no desenho, onde Cláudia, por um instante de "inspiração" 15 , arrisca-se, risca e arrisca um novo gesto, um movimento desconhecido em relação ao leque de movimentos empreendidos na atividade. Ainda que resistente, aceita o desafio proposto pelo coordenador e cria um risco completamente diferente dos que vinha utilizando em seu desenho, uma forma divergente que rompe uma estrutura estereotipada, que surge como um raio, rasgando o horizonte que havia sido fechado por um padrão estético pré-estabelecido. Um rabisco que materializa toda a intensidade afetivo-cognitiva-motora de um processo inicial de abertura, intensidade relampejante que o olhar percebe apropriadamente, apropriando-se significativamente, não como uma simples risco, mas como um corisco.

A mediação de Jacques foi fundamental nesse processo, pois o raio desenhado por Cláudia surgiu como um "relâmpago" resultante do choque entre duas nuvens de cargas opostas, entre dois modos diversos de percepção: o da aluna e o do artista/professor, de modo que o sentido do raio vai além de ser um sinônimo de corisco: é também um $\mathrm{co} /$ risco, um risco compartilhado, coletivamente produzido num processo em que a intervenção do educador foi fundamental.

Jacques propõe mediações que permitem enfrentar as concepções tradicionais de expressão artística, nas quais o sujeito imprime sua marca no papel, na pedra, na argila como coação e não como ação conjunta. O mediador propõe "ação com" ao significar a linha desenhada por Cláudia como algo novo e que se apresenta como tal de maneira paradoxal: o que era para destruir, construiu. Ao transformar-se em signo do novo, a linha trouxe a possibilidade de não ser forjada somente, mas de imprimir ao gesto e à vontade do sujeito, novos gestos, novas vontades.

A mediação semiótica, engendrada pelo artista/educador ao instrumentar Cláudia a transformar a "natureza" da linha, ou seja, aquilo que é "natural" de se fazer com linhas desenhadas, permitiu que ela também se transformasse. Desestabilizou-se ao desestabilizar a forma de gravar marcas no papel e, nesse movimento, permeado pela confrontação com o olhar do outro, pôde também refletir e re-ver o próprio olhar.

\section{Referências}

Blanchot, M. (1987). O espaço literário. Rio de Janeiro: Rocco.

Bordieu, P. (1996). A gênese social do olho. Em P. Bordieu (Org.), As regras da arte: Gênese e estrutura do campo literário (pp. 348-356). São Paulo: Companhia das Letras. 
Dessen, M. A. (1995). Tecnologia de vídeo: Registro de interações sociais e cálculos de fidedignidade em estudos observacionais. Psicologia: Teoria e Pesquisa, 11, 223-227.

Góes, M. C. (2000). A abordagem microgenética na matriz histórico-cultural: Uma perspectiva para o estudo da constituição da subjetividade. Cadernos Cedes, 50, 9-25.

Luria, A. (1979). Curso de psicologia geral. Rio de Janeiro: Civilização Brasileira.

Meira, L. (1994). Análise microgenética e videografia: Ferramentas de pesquisa em psicologia cognitiva. Temas em Psicologia: Questões Teórico-metodológicas, 3, 5971.

Oliveira, H. L. P. (1996). O Real dá-se ao Olhar: Perspectiva e visualização da verdade nas imagens da Renascença. Revista Catarinense de História, 4, 146161.

Peixoto, N. B. (1999). O olhar do estrangeiro. Em A. Novaes (Org.), O Olhar (pp. 361-365). São Paulo: Companhia das Letras.

Pino, A. (1991). O conceito de mediação semiótica em Vygotsky e seu papel na explicação do psiquismo humano. Cadernos Cedes, 24, 32-43.

Pino, A. (1995). Semiótica e cognição na perspectiva histórico-cultural. Temas em Psicologia, 2, 31-40.
Teplov, R. M. (1977). Aspectos psicológicos de educação artística. Em A. Luria, A. I. Leontiev, L. Vygotsky \& cols. (Orgs.), Psicologia e pedagogia II: Investiga1 ções experimentais sobre problemas didáticos especificos (pp. 123-153). Lisboa: Estampa.

Vázquez, A. S. (1999). Convite à estética. Rio de Janeiro: Civilização Brasileira.

Vygotsky, L. (1990). La imaginacion y el arte en la infancia. Madrid, ES: Akal.

Vygotsky, L. (1992). Obras escogidas II: Pensamiento y lenguaje. Madrid, ES: Visor.

Vygotsky, L. (1995). Obras escogidas III: Problemas del desarrollo de la psique. Madrid, ES: Visor.

Vygotsky, L. (2001). A construção do pensamento e da linguagem. São Paulo: Martins Fontes.

Sobre os autores

Alice Casanova dos Reis é Acadêmica de Psicologia, bolsista de IC-CNPq/UFSC Florianópolis.

Andréa Vieira Zanella é Professora do Departamento e do Programa de Pós-Graduação em Psicologia da Universidade Federal de Santa Catarina.

Kelly Bedin França é Acadêmica de Psicologia, bolsista de IC-CNPq/UFSC.

Sílvia Zanatta Da Ros é Professora do Departamento de Estudos Especializados e Pós-

Graduação em Educação da Universidade Federal de Santa Catarina. 